\title{
Mercosul aos dez anos: crise de crescimento ou perda de identidade?
}

\author{
ALCIDES COSTA VAZ*
}

\section{Introdução}

Ao cumprirem-se dez anos de sua criação, o Mercosul atravessa sua mais abrangente e profunda crise, mas exibe, ao mesmo tempo, resultados que o diferenciam claramente de quaisquer outras iniciativas de integração econômica empreendidas na América Latina. O balanço de seus resultados e o delineamento de suas perspectivas mostra-se muito mais complexo que o simples confronto dos objetivos enunciados no Tratado de Assunção com o estágio alcançado com a construção de um regime de livre comércio e de uma união aduaneira imperfeita. Tampouco pode resultar de uma leitura generosa dos indicadores do comércio intra-zonal e global. Deve tomar em conta aspectos internos e externos que condicionam o desempenho econômico do bloco em seu conjunto e dos respectivos países membros, notadamente de Brasil e Argentina. Ao mesmo tempo, devem ser considerados fatores de ordem política que orientam as ações dos governos, em resposta a oportunidades e riscos da integração e às demandas e expectativas dos setores por ela interessados e mais diretamente afetados. Desse modo, o Mercosul deve ser entendido como resultante de uma interação complexa, embora nem sempre coerente, de forças estruturais e fatores conjunturais presentes nos planos global, regional e doméstico simultaneamente.

Na presente análise são destacadas as características mais relevantes do Mercosul em sua evolução recente e a associação desta com o desempenho econômico de suas duas principais economias e com os diferentes ciclos de crescimento econômico coincidentes e não coincidentes entre elas observados nos últimos dez anos. Nesse plano, particular ênfase é prestada aos esforços voltados para o estabelecimento e preservação da estabilidade econômica, em um primeiro momento, e para o crescimento econômico, em seguida, bem como ao tratamento de temas comerciais nos planos bilateral e subregional como principais 
condicionantes, no campo econômico, da agenda e da dinâmica internas do Mercosul. Em face dos desafios externos e dos crescentes constrangimentos de ordem econômica que o bloco vem enfrentando nos últimos anos, os países membros vêem-se frente a um dilema: a necessidade de renunciar ao exercício da discricionalidade na condução de políticas públicas, em um contexto marcado, em grande medida, por incertezas econômicas, para favorecer a pretendida consolidação do Mercosul, precisamente quando, por contingências econômicas domésticas e externas, as autoridades econômicas passam a valorizar essa mesma discricionalidade para fornecer respostas aos problemas que enfrentam.

\section{Desempenho e perspectivas econômicas: impactos sobre o comércio, investimentos e a competitividade internacional}

Quanto aos seus objetivos e resultados no plano comercial, o Mercosul pode ser considerado relativamente bem sucedido, notadamente quanto aos seus efeitos estáticos. De acordo com a Secretaria Geral da ALADI, o comércio intraMercosul cresceu 336\% na última década, evoluindo US\$ 4.1 bilhões registrado em 1990, ano que antecedeu a criação do bloco, para US\$ 18.2 bilhões em 2.000, após haver alcançado a cifra recorde de US\$ 20.5 bilhões em 1997 e ter decrescido para US\$ 15.3 bilhões em 1999 em conseqüência da desaceleração econômica observada em toda a região que se seguiu à desvalorização cambial brasileira. Esse desempenho, no entanto, contrasta com o das exportações do bloco para outras regiões. Entre 1990 e 2.000, as vendas externas do bloco cresceram somente cerca de 50\%, saindo do nível de US\$ 42.3 bilhões para US\$ 61 bilhões, enquanto as importações aumentaram 180\%, alcançando US\$ 65 bilhões no ano 2.000 contra a cifra de US\$ 23.1 bilhões registrada uma década antes.

O maior dinamismo das importações ampara o argumento de que o Mercosul representa uma iniciativa de regionalismo aberto. No entanto, análises recentes e mais acuradas revelam a prevalência do desvio sobre a criação de comércio no crescimento do comércio intra-Mercosul nos anos noventa, refletindo não apenas a persistência de formas de proteção contra importações de terceiros países mas também de restrições ao comércio intra-regional que limitam as possibilidades de criação de comércio. A esse respeito, é importante notar que o progresso que se pode alcançar na eliminação e harmonização de barreiras não tarifárias dentro do bloco se vê diluído por práticas de comércio regulado que, por sua vez, contrabalançam os efeitos estáticos e dinâmicos do grande crescimento do comércio.

A prevalência do desvio de comércio também se choca com os efeitos dinâmicos da integração econômica. O Mercosul certamente tem contribuído para expandir oportunidades comerciais, estimular atração de capitais e dinamismo 
econômico em geral, mesmo em períodos em que uma de suas principais economias enfrentam taxas muito baixas de crescimento econômico ou mesmo recessão, como ocorrido com o Brasil no período 1990-1992 e a Argentina de 1998 ao presente. No entanto, deve-se recordar que a estabilização econômica e as reformas conduzidas no início dos noventa, incluindo os grandes programas de privatização nos dois países - e não a integração econômica em si - foram as principais forças dinamizadoras e fontes de estímulo para o ingresso de capitais e para o crescimento econômico. A integração regional jogou um papel positivo mas secundário ao estar voltada para os objetivos primários de alcançar e preservar a estabilidade macroeconômica e abrir as economias. Nesse sentido, o Mercosul pode ser considerado muito mais um canal ou fonte complementar de dinamismo econômico. Também jogou papel limitado na promoção da competitividade internacional da produção regional. A esse respeito, cabe notar que, apesar do impressionante aumento do comércio intra-Mercosul, o comércio bilateral do Brasil com seus sócios do Mercosul ainda exibe um padrão tradicional, com o Brasil exportando produtos manufaturados e importando commodities, mesmo tendo se tornado o principal destino das exportações de manufaturas da Argentina. Esse mesmo padrão persiste nas exportações do Mercosul para outros países e regiões.

O limitado papel do Mercosul em estimular a competitividade das exportações regionais torna-se claro quando se consideram as dificuldades do Brasil em aumentar suas exportações de manufaturados especialmente para os mercados do Primeiro Mundo. Deve-se notar que a América Latina representou o mercado mais dinâmico para as exportações industriais brasileiras e o único no qual elas expandiram na última década. Tais dificuldades estão relacionadas, indubitavelmente, às barreiras comerciais que afetam importantes produtos de exportação da região e do País; no entanto, as várias razões endógenas para a falta de competitividade das importações industriais do Mercosul não podem ser negligenciadas. Em síntese, o Mercosul desempenhou um papel positivo mas limitado em promover a competitividade internacional das economias nacionais por meio do aumento das oportunidades comerciais, dos fluxos de investimentos e de uma mais eficiente alocação de recursos, mas não de forma suficiente para permitir a expansão substantiva das exportações industriais para terceiros países e regiões.

\section{Ciclos de crescimento e panorama recente das economias de Brasil e Argentina.}

Nos últimos dois anos, Brasil e Argentina enfrentaram o esgotamento final das políticas com as quais alcançaram, em diferentes momentos, a estabilidade econômica. Para ambos países, tal processo coincidiu com a deterioração de suas respectivas contas externas, para o que concorreu a turbulência financeira decorrente da crise que assolou as economias asiáticas e russa em 1997 e 1998, e que alcançou 
também a América do Sul naquele mesmo ano, onde culminou com a desvalorização da moeda brasileira no início de 1999. No Brasil, seguiu-se um período de adaptação do mercado e dos setores produtivos ao novo contexto macroeconômico, com as autoridades econômicas voltadas para o controle da inflação e para a restauração da confiança dos agentes de mercado e dos investidores estrangeiros na economia brasileira, uma vez que o ajuste procedido afetou diretamente um dos principais pilares da estabilidade econômica alcançada em 1994, qual seja, a política cambial.

Apesar da persistência de desequilíbrios nas contas públicas e das expectativas sempre frustradas de reversão do déficit comercial que o País vem acumulando, o mercado interno retomou dinamismo, favorecido, de um lado, pelo aumento das exportações e, internamente, por uma política monetária menos restritiva e austeridade fiscal. Desse modo, a economia brasileira pode iniciar, ainda ao longo de 1999, uma nova fase de expansão econômica em bases mais sustentáveis, o que esteve refletido no crescimento de $4 \%$ registrado em 2.000 e em projeção semelhante para 2001, agora revista em razão dos efeitos esperados da crise energética sobre o setor produtivo.

Na Argentina, por sua vez, a estagnação econômica segue-se à recessão iniciada no segundo semestre de 1998 e aprofundada, dentre outras razões, com a desvalorização cambial brasileira do início de 1999, em que pesem as sucessivas tentativas do Governo de Fernando De La Rua em melhorar o desempenho fiscal e cortar gastos públicos. A balança comercial argentina exibe sinais de equilíbrio graças fundamentalmente ao melhor desempenho das exportações e à recuperação do preço de algumas comodities (principalmente o Petróleo), o que permitiu a gradual redução de seu déficit comercial. Por outro lado, as dificuldades em financiar déficits de conta corrente que alcançaram 4\% do PIB em 2.000 ainda persistem, apesar da "blindagem” de US\$ 40 bilhões capitaneada pelo Fundo Monetário Internacional e por governos da OCDE. A retomada do crescimento econômico acha-se dependente do êxito da operação de troca de títulos de dívida pública com a qual as autoridades econômicas esperam afastar a perspectiva de moratória e reangariar a confiança dos investidores estrangeiros.

O desempenho recente das duas maiores economias do Mercosul indica que as mesmas estão, uma vez mais, enfrentando ciclos invertidos de crescimento econômico. Cumpre assinalar que em sete dos dez últimos anos (1991-93, 1995, 1998, 1999 e 2.000) esse mesmo padrão foi observado. Três deles (1995, 1998 e 1999) estiveram diretamente relacionados à instabilidade no sistema financeiro internacional e às suas conseqüências para as economias de ambos países, enquanto os demais podem ser atribuídos a diferentes condições macroeconômicas domésticas e a desequilíbrios microeconômicos, como parece ser o caso presente.

Assim, o desempenho econômico do Mercosul está fortemente associado no presente à possibilidade de a economia brasileira manter algum nível significativo 
de crescimento econômico como forma de abrandar as vicissitudes enfrentadas pela Argentina e de conferir alento ao processo de integração. A perspectiva de estagnação ou mesmo de recessão econômica generalizada compromete a possibilidade de quaisquer avanços efetivos na consolidação e aprofundamento do bloco no futuro mediato.

Na fase de transição, a trajetória do Mercosul teve como um de seus principais condicionantes, os esforços dos governos em alcançar e preservar a estabilidade macroeconômica. As estratégias promovidas com vistas à consecução daquele objetivo geraram contexto pouco propício para a coordenação macroeconômica freqüentemente reclamada por aqueles que propugnavam o avanço do processo de integração para além da área comercial em que estiveram concentrados os esforços durante todo o período de transição e também nos anos seguintes. Uma vez alcançada a estabilidade macroeconômica, a atenção dos governos, por força das circunstâncias externas, voltou-se para sua preservação em face, sobretudo, dos impactos advindos de sucessivas crises financeiras externas (México em 1995, Sudeste Asiático, 1997, Rússia, 1998).

O esforço de preservação da estabilidade econômica e de promoção de crescimento teve como contrapartida crescentes níveis de déficits em conta corrente, de dívida pública e do endividamento externo dos dois países, de sorte que, no presente, são essas as questões - além da retomada/preservação de crescimento econômico em bases sustentadas - e as vulnerabilidade das economias nacionais e do próprio Mercosul frente a crises externas, que concentram as atenções das autoridades econômicas dos países membros.

Diferentemente dos anos iniciais, quando por força das idiossincrasias dos respectivos modelos de estabilização implementados, a capacidade dos governos de, ofertarem níveis de coordenação macroeconômica era muito limitada, no presente, a necessidade, para ambos países, de exercer controle sobre gastos públicos e sobre níveis de preços incentivou os governos a empreenderem passos iniciais rumo à coordenação macroeconômica. Embora não seja factível nas circunstâncias presentes, sobretudo quando tornam-se evidentes as diferentes visões sobre o Mercosul no seio do governo argentino, o tema da coordenação macroeconômica segue na agenda do bloco.

No entanto, a questão central a esse respeito diz respeito à disposição efetiva dos governos em abrir mão da pouca margem de discricionalidade que lhes resta na formulação e condução de políticas econômicas em um contexto de instabilidade doméstica e de grande volatilidade no plano externo. A retrospectiva do bloco não avaliza otimismo a esse respeito. No passado, e ainda no marco de um contexto econômico global bem mais favorável, e também coincidindo com um dos períodos de ciclos invertidos (91-93), a opção, por exemplo, do governo argentino em face dos déficits comerciais que vinha acumulando, particularmente com o Brasil, bem como dos custos da abertura unilateral e daquela empreendida no 
âmbito do Mercosul para alguns setores foi de procurar resguardar margem de discricionalidade no âmbito comercial que, por força do modelo econômico implantado a partir de abril de 1991, passou a ser praticamente o único onde essa podia ser exercida. Isso acarretou dificuldades frente ao Brasil, particularmente no contexto das negociações dos temas ancilares à área de livre comércio e, principalmente, da união aduaneira, à qual a Argentina procurou resistir.

O mesmo padrão de comportamento ocorreu com o Brasil em diferentes momentos, levando à persistência de posturas unilaterais, em última instância incompatíveis com a disciplina comercial comunitária que se procurava instaurar e consolidar, ensejando, eventualmente, práticas protecionistas disfarçadas ou explícitas e que seguem no bojo dos sucessivos conflitos comerciais que vêm marcando a evolução do Mercosul nos últimos anos.

Cumpre também assinalar que, excetuando o ano de 1994, quando culminaram as negociações que resultaram na implantação da união aduaneira e na definição do arcabouço institucional do Mercosul que entrariam em vigor a partir de 1995, (ainda que de forma limitada, quanto à primeira), o período de crescimento simultâneo (1996-97) não foi bem explorado no sentido de preparar caminho para a pretensamente almejada coordenação macroeconômica entre os dois principais sócios do Mercosul, e muito menos ainda entre os quatro países membros. Naquele biênio, prevaleceu a perspectiva pragmática da conveniência de seguir administrando as relações comerciais segundo os parâmetros e mecanismos que haviam sido consagrados no Protocolo de Ouro Preto, sob o argumento da necessidade de consolidar e aperfeiçoar a área de livre comércio e a união aduaneira, não se identificando, então, estímulos para envidar maiores esforços para iniciar a transição para o mercado comum.

Na ausência de estímulos endógenos, não surpreende ter sido, naquele contexto, os elementos da agenda externa do bloco, particularmente as negociações da ALCA, o mais poderoso, senão os únicos estímulos capazes de instar (ainda que de modo desigual) os países do Mercosul a procurarem contrapor-se à inércia interna que se instaurara a partir da assinatura do Protocolo de Ouro Preto em dezembro de 1994. Conformou-se, assim, um quadro ambíguo que perdura até os dias de hoje: de um lado, a dimensão estratégica do Mercosul termina associada quase que exclusivamente às suas vinculações e possibilidades externas, seja enquanto plataforma negociadora com a qual seus membros procuram reduzir as assimetrias que marcam suas relações, individualmente, com seus principais parceiros econômicos, seja como eixo de articulação, no âmbito regional, e com os principais pólos dinâmicos da economia mundial. Assim, o Mercosul termina afastando-se do sentido de construção de um projeto comum de desenvolvimento e de transformação produtiva que presidiu seu surgimento e os primeiros anos de sua trajetória; simultaneamente, a agenda interna terminou centrando-se nos temas 
comerciais - notadamente os inúmeros conflitos bilaterais que terminaram ditando percepções negativas sobre o bloco - com esparços avanços em áreas específicas.

Nesse sentido, observa-se haver um significativo descompasso entre as agendas doméstica e externa do Mercosul, bem como entre essas agendas e o objetivo formal do Tratado de Assunção: a livre movimentação de bens, serviços, capital e mão de obra dentro da região. Esse descompasso se acentua ainda mais quando, devido a demandas setoriais e desequilíbrios macro e/ou microeconômicos, os governos recorrem a medidas unilaterais, gerando ou exarcebando conflitos que, ademais de contaminarem as percepções internas e externas sobre o bloco, terminam revelando também fragilidades institucionais, como exemplificam a crise desencadeada com a desvalorização da moeda brasileira, as sucessivas disputas comerciais que se seguiram e a decisão recente do Governo argentino de unilateralmente alterar a tarifa de importação para bens de capital e bens de consumo finais, perfurando ainda mais (mesmo que em regime temporário) a tarifa externa comum.

Uma vez que os avanços no plano das relações externas têm se revelado complexos e morosos - como o demonstram as negociações com a União Européia, no âmbito do Acordo Quadro firmado em 1995, e as negociações há pouco retomadas com a Comunidade Andina - ou implicam controvérsias e riscos, como é o caso da ALCA, e que, por outro lado, a dinâmica do comércio intra-Mercosul e do bloco com outros países e regiões passou a estar fortemente condicionada às injunções econômicas domésticas mais que à capacidade de indução do próprio Mercosul, este parece ter perdido a força propulsora e o dinamismo que marcaram sua trajetória inicial, daí o conseqüente desgaste que o bloco sofreu a partir de 1998 e que se traduz na acentuada erosão de sua credibilidade frente às sociedades de seus países membros e à comunidade internacional.

No entanto, o Mercosul continua tendo alto valor simbólico e potencialidades para voltar a representar elemento dinamizador e potencializador das capacidades econômicas de seus membros. Continua a ser considerado instrumento útil de realização de interesses e objetivos nacionalmente definidos e regionalmente conformados. De tal sorte que, as chances de revigoramento do bloco parecem depender no curto prazo, muito mais que em períodos anteriores do afiançamento político dos governos, de um amplo respaldo social e da possibilidade de estreitar e de projetar e fortalecer cooperação em diferentes domínios para ancorar o processo até que estejam dadas condições mais propícias de restaurar sua disciplina econômica. No entanto, e em última instância, a perspectiva do Mercosul enquanto mecanismo de integração continua repousando na disposição ainda não plenamente manifestada dos governos de renunciar à unilateralidade e a práticas discricionárias em matérias econômicas com as quais têm respondido aos desequilíbrios macroeconômicos, aos problemas suscitados pela própria integração no plano 
microeconômico e, por fim, às vicissitudes impostas por conjunturas externas adversas. Tal renúncia se daria em prol de uma disciplina econômica comum que permitisse inscrever de modo efetivo na agenda das negociações os temas relacionados à estruturação de um mercado comum, único objetivo capaz de fazer o Mercosul voltar a mobilizar interesses de modo mais amplo, de resgatar o dinamismo e a capacidade de induzir mudanças no tecido político, econômico e social dos países membros que o Mercosul exerceu no passado, e de evitar sua própria e lenta autodissolução, seja por inanição, seja por força de novos arranjos de liberalização comercial que o suplantem, como no caso a ALCA.

A opção pelo revigoramento e aprofundamento do bloco implica, primeiramente, uma forte aposta na integração econômica como forma de manejarse em um contexto de volatilidade econômica e, consequentemente, de incertezas. Em segundo lugar, a aceitação de fórmulas institucionais mais elaboradas que outorguem maior grau de segurança jurídica e que permitam o aperfeiçoamento de sua dimensão multilateral na realização de funções ainda não adequadamente cumpridas. Cumpre assinalar a esse respeito que a fórmula multilateral do Mercosul tem atendido satisfatoriamente aos problemas de colaboração entre os países membros, mas não responde de igual modo aos problemas de coordenação, de estruturação e simplificação de agendas.

Até o presente, as posições dos governos em relação a essas questões têm sido marcadas pela ambigüidade. Há, de um lado, o recorrente afiançamento do compromisso com a continuidade do processo de integração, embora os termos e as condições para tantos sejam percebidas de forma diferenciada em cada país. Há também disposição política para procurar superar o quadro de estagnação que assola o Mercosul, como o demonstram as propostas de relançamento emanadas da última presidência pró-tempore argentina e as iniciativas de harmonizar os critérios de formação dos indicadores econômicos e das estatísticas nacionais, com o que se pretende abrir passo para a definição de metas econômicas comuns em torno das quais se possa encaminhar as ações de coordenação macroeconômica. De outro lado, porém, observa-se a recorrência de ações unilaterais e de medidas restritivas ao comércio, além da consagração de formas de comércio regulado, como os acordos de restrição voluntária de exportações. Esses fatos revelam a alta permeabilidade dos governos às demandas setoriais por tratamento excepcional e que se acentuam notadamente nos momentos de crise econômica e de instabilidade política. Revelam também dificuldades de conciliar interesses que nutriram-se da negligência benevolente para com o tratamento de questões afetas à política industrial dos dois países e que ganham relevo quando o crescimento econômico irrompe como objetivo fundamental para cada um dos países. Dessa forma, torna-se particularmente complexo o esforço de restaurar e consolidar a tarifa externa comum. Três grandes desafios apresentam-se nesse âmbito, segundo João Bosco 
Machado: a preservação de vantagens comparativas nos setores que caracterizam o padrão de inserção internacional das economias do Mercosul; a reestruturação ou reconversão produtiva dos setores de competitividade cadente e daqueles afetados pelo processo de integração regional e a criação de vantagens comparativas no marco do mercado ampliado, favorecendo setores que apresentem maior conteúdo tecnológico e maior dinamismo no comércio internacional.

Em relação à revisão da estrutura jurídico-institucional, embora haja amplo reconhecimento das limitações do atual arranjo e da necessidade de aprimorá-lo, sobretudo no que compete ao sistema de resolução de controvérsias, ainda pairam resistências, sobretudo da parte brasileira, quanto à introdução de componentes de supranacionalidade no bloco, estando as perspectivas mais imediatas nesse campo, adstritas ao aperfeiçoamento do Tribunal Arbitral, sem, contudo, configurar rompimento com os moldes com que este tem funcionado.

Por fim, é preciso observar que há uma importante mudança de comportamento de parte dos chamados "sócios menores” que vêm procurando exercer um protagonismo mais ativo em torno de questões, muitas das quais tradicionalmente tratadas bilateralmente entre Brasil e Argentina e subseqüentemente negociadas com os demais, como por exemplo o regime automotivo, o que torna mais complexas as negociações e o processo decisório. Não são suficientemente claras ainda as implicações, a esse respeito, de um eventual alargamento do bloco mediante a anunciada e em seguida adiada, mas não definitivamente descartada incorporação do Chile como membro pleno, e o acatamento do já formalizado pleito venezuelano de associar-se à área de livre comércio eventualmente, do ponto de vista do processo decisório. A conjunção do maior protagonismo de Uruguai e Paraguai com a perspectiva de ampliação do bloco levará Brasil e Argentina a ter que confrontar a questão da institucionalidade do bloco para além dos termos em que a mesma tem sido tratada até o momento, de forma a dotar o Mercosul de uma autêntica expressão multilateral.

De forma mais imediata, porém, o desafio, do ponto de vista político, consiste em reacoplar o Mercosul, de forma construtiva, às agendas política e econômica domésticas e, ao mesmo tempo, revalorizá-lo como espaço privilegiado para a concertação de posições em um conjunto crescente de interesses e posições de política exterior, resgatando, embora em um contexto em muitos sentidos bastante diverso daquele no qual o bloco foi criado, seus objetivos originais e sua funcionalidade geral como elemento indutor de dinamismo político e econômico e como expressão e componente indeclinável de um projeto político, em sua acepção maior, de interesse dos países que o conformam.

No que se refere ao primeiro aspecto, insistir no tratamento do conjunto dos temas constantes na agenda do relançamento constitui um passo decisivo para restaurar a disciplina comercial do Mercosul, tanto no tocante ao regime de livre 
comércio quanto à união aduaneira, com externalidades positivas em termos econômicos e políticos. Ao mesmo tempo, porém, restaurar e consolidar a disciplina comercial do bloco demandará maior coordenação de esforços em outras áreas, como, políticas industriais, de modo a evitar a recorrência de medidas de comércio regulado contrárias ao sentido que se pretende imprimir ao bloco. Sob esse ponto de vista, afora as vicissitudes econômicas ora enfrentadas e que militam fortemente contra o revigoramento do bloco, a agenda do relançamento parece reconfirmar a opção, por muitos considerada minimalista, que vem presidiu a trajetória de dez anos do bloco, uma vez que não há referências, na agenda proposta, a outros âmbitos de atuação afora o econômico-comercial e o institucional. Observa-se assim a falta de referência a iniciativas que se possam conduzir em outros domínios e, sobretudo, à incorporação de uma agenda abarcativa de interesses e temas de maior apelo social.

As possibilidades quanto às vinculações externas também colocam oportunidades importantes, mas a factibilidade de sua realização se projeta em prazos maiores que aqueles requeridos para o revigoramento do bloco. Dentre as diferentes vertentes de negociação em curso ou contempladas para o futuro próximo, a que oferece melhores condições para um protagonismo mais autônomo e de realizações paupáveis em termos de integração é a aquela voltada para o espaço sul-americano, muito embora seja forçoso reconhecer ser necessário descaracterizar o projeto de articulação e integração do espaço sul-americano como desígnio que atende mais aos interesses brasileiros ou como simples expansão do próprio Mercosul. A ALCA, particularmente com as definições alcançadas na Reunião Ministerial de Buenos Aires e na Cúpula de Toronto, por sua vez, segue representando um estímulo e um fator de pressão para a consolidação e aprofundamento do Mercosul, muito embora não induza à estruturação de uma agenda em tal sentido. As negociações com a União Européia continuam revelando diferenças significativas quanto à estrutura dos interesses entre as partes e ao alcance das negociações. Apesar do recente progresso induzido pela ALCA nas negociações entre Mercosul e União Européia, não está clara a extensão da disposição da parte européia quanto a um acordo com o Mercosul frente à maior premência que assume a vinculação de países da Europa Oriental.

Para além do componente comercial presente nas negociações com outros países e blocos econômicos, a agenda externa do Mercosul contempla formas de diálogo político e de cooperação econômica e em outros campos que são igualmente importantes de serem consideradas no delineamento das possibilidades de sua evolução futura e de sua consolidação. Nesse sentido, a agenda com a União Européia e aquela definida por ocasião da Cúpula Sul-Americana celebrada no segundo semestre de 2.000 são exemplos claros das chances de conectar organicamente as agendas externa e interna do bloco. 


\section{Conclusões}

Portanto, e por mais paradoxal que seja em face do atual quadro econômico nos quatro países membros, parecem estar no plano interno as oportunidades efetivas para o revigoramento do Mercosul, sendo este também o âmbito em que os governos usufruem de melhores possibilidades de atuarem proativamente, dado que, em outros, como o de suas vinculações externas, tal possibilidade se vê restringida por fatores que se lhes escapam ao controle. Além do mais, na medida em que sua estrutura interna se fortaleça, como estímulo e resposta a uma maior interdependência que se projete para além do domínio comercial, a agenda interna do Mercosul reincorporará a dimensão e o sentido estratégico hoje quase que exclusivamente associados ao plano de suas vinculações externas, em benefício da consecução de um projeto de desenvolvimento regional.

Desse modo, a alternativa restante ao Mercosul que não a estagnação e o retrocesso associa-se ao esforço de avançar parcial e gradualmente no sentido de seu objetivo original, o que o levará a assumir uma configuração híbrida, espelhando os desafios, os dilemas e impasses do trânsito de um esquema preponderantemente comercial, hoje materializado na união aduaneira imperfeita, para formas mais abrangentes e profundas de integração, as quais, mesmo não chegando a configurar cabalmente o pretendido mercado comum, o diferenciarão qualitativamente de sua configuração atual.

Junho de 2001

\section{Bibliografia}

BOUZAS, Roberto. Las perspectivas del Mercosur: desafíos, escenarios y alternativas para la proxima decada. Buenos Aires: FLACSO, 1999.

CAMPBELL, Jorge (ed.). Mercosur: entre la realidad y la utopia. Buenos Aires: Grupo Editor Latinoamericano, 1999.

DEVLIN, Robert \& Ffrench-Davis, Ricardo. Towards na evaluation of regional integration in the 90's. Buenos Aires: INTAL, Dissemination Paper n. 8, 1999.

GARNELO, Vicente. Evolución institucional y jurídica del Mercosur. Buenos Aires: INTAL, Dissemination Paper, n. 3, 1998.

LIMA, Marcos C. \& MEDEIROS, Marcelo Almeida (Org.). O Mercosul no limiar do Século XXI. São Paulo: Cortez Editora, 2.000.

INTAL. Informe Mercosul: Período 1999-2000. Informe n. 6. Banco Interamericano de Desenvolvimento: Buenos Aires, September, 2.000.

MACHADO, João Bosco M. Mercosul: Processo de Integração: Origem, Evolução e Crise. São Paulo: Edições Aduaneiras, 2.000.

NAGARAJAN, Nigel. On the evidence of trade diversion in Mercosur. European Commission Directorate-General for Economic and Financial Affairs. Bruxelas, 1998.

TIRADO MEJÍA, Alvaro. Integración y Democracia em America Latina y el Caribe. Buenos Aires: INTAL. Informe INTAL n. 8, 1999. 
Resumo

O texto analisa a trajetória de uma década do Mercosul e suas perspectivas de médio prazo em suas dimensões econômica e político-institucional, com ênfase aos reflexos de injunções internas e externas para o desempenho das duas principais economias do bloco e às respostas dos respectivos governos às oportunidades e constrangimentos para a consolidação do bloco.

\section{Abstract}

The text analyses the course of Mercosur along its first decade as well as its mid-term perspectives in economic, polical and institutional terms, with emphasis on the consequences of internal and external injunctions to the performance of its two main economies and the responses of the respective governments to opportunities and restraints towards the bloc's consolidation.

Palavras-chave: Mercosul. Integração Econômica Regional. Key words: Mercosur. Regional Economic Integration. 